\title{
Critical Fantasy Studies
}

Jason Glynos

(University of Essex)

(Accepted for publication in the Journal of Language and Politics)

Ref: Glynos, J. (2021) 'Critical Fantasy Studies', Journal of Language and Politics 20(1).

https://www.jbe-platform.com/content/journals/10.1075/ilp.20052.gly

\begin{abstract}
Many scholars have drawn attention to the affective power that aspects of discourse and practice exert in our social and political life. Fantasy is a concept that, like structures of feeling, rhetoric, myth, metaphor, and utopia, has generated illuminating explanatory and interpretive insights with which to better understand the operation of this power. In this piece I argue that there are distinctive virtues in affirming the value of the category of fantasy, from a theoretical point of view. Importantly, however, I also argue that the qualification 'critical' in Critical Fantasy Studies captures something about how such studies can draw out the normative, ideological, and politico-strategic implications of psychoanalytic insights and observations, and thus become part of a broader enterprise in critical theoretical and empirical research.
\end{abstract}

\section{Key words}

Fantasy; discourse theory; poststructuralism; discourse analysis; post-marxism; normative critique; critique of ideology 


\section{Introduction}

Many scholars have drawn attention to the affective power coursing through social and political life. Fantasy is a concept that, like structures of feeling, rhetoric, myth, metaphor, and utopia, has generated illuminating explanatory and interpretive insights with which to better understand the operation of this power. It is often tempting to regard the fantasmatic aspects of social and political life as mere false representations of reality, but the critical significance of fantasy can be grasped differently. In this piece I argue that there are distinctive theoretical virtues in affirming the value of the psychoanalytic category of fantasy. Importantly, however, I also argue that the qualification 'critical' in Critical Fantasy Studies captures something about how such studies - through their appeal to post-Marxist discourse theory - point to the normative, ideological, and politico-strategic implications of psychoanalytic insights and observations, and thus become part of a broader enterprise in critical theoretical and empirical research. ${ }^{1}$

I will first sketch out how we can understand critical fantasy studies as a frontier of postMarxist discourse theory, pointing briefly to some important affinities between post-Marxist discourse theory and critical theory, as elaborated in the Frankfurt School tradition. I also situate in a more precise fashion the turn to fantasy within the poststructuralist horizon of post-Marxist discourse theory, conceived as a species of critical political theory. I then outline some key features of fantasy with reference to adjacent notions, particularly enjoyment. I do this in order to underline the insights made possible by a psychoanalytic understanding of this category, moving on to consider the critical aspects of Critical Fantasy Studies. In my discussion of each of the conceptual and critical dimensions of critical fantasy studies, I outline a set of challenges confronting discourse theory, pointing to possible avenues of future research. I conclude with a caveat designed to guard against the perils of a kind of psychoanalytic imperialism that would emphasize the fantasmatic dimension of life at the expense of, rather than as a supplement to, other dimensions of social and political life, indicating how this brings into view a broad comparative, transdisciplinary research agenda.

\section{Critical Fantasy Studies as a frontier of post-Marxist discourse theory}

Few would deny the considerable impact the Frankfurt School's use of Marx and Freud has had on our thinking about critique and empirical research in the humanities and social sciences. The increased attention paid to right-wing economic and nationalist rhetoric since the global financial crash, not to mention the so-called 'populist moment', marks yet another conjuncture calling for a return to the Frankfurt School classics in order to re-tarry with chestnut issues of a theoretical, methodological, and critical character, concerning authoritarianism and fascism, monopoly capitalism, anti-Semitism, consumerism, and

\footnotetext{
${ }^{1}$ As far as I am aware the term 'critical fantasy studies' appeared for the first time at the 2012 conference of the Association for the Psychoanalysis of Culture and Society, in the context of a series of panels eliciting psycho-social perspectives on the effects of neoliberalism and the hatred of government, organized by Lynne Layton, whose own work shares strong affinities with such an endeavour (see Layton 2020).
} 
positivist understandings of theory/praxis and subjectivity/objectivity relations (Morelock 2018; Best et al. 2018).

Since the (early) Frankfurt School burst on the scene with its unique mix of Freudian and Marxian thought, there have been many efforts to mine the rich terrain defined by the intersection of psychoanalysis and the critique of political economy, for example by taking into account structuralist, poststructuralist, deconstructionist and post-Freudian interventions. Post-Marxist discourse theory instantiates one such iteration, as it also seeks to articulate a critique of traditional Marxism with psychoanalytic insights, pushing this however in the direction of a critical political theory set within a poststructuralist framework. Critical fantasy studies can thus be understood as a means of amplifying one particular frontier of post-Marxism, at the cross-roads of poststructuralist discourse analysis and psychoanalysis. The importance of such cross-fertilization for post-Marxist discourse theory is something that Laclau and Mouffe have themselves emphasized (Laclau and Mouffe 1985; Laclau 1990), but its significance has also been registered and reinforced by other scholars, such as Zizek (1989) and Stavrakakis (1999), provoking an increasing number of related scholarly outputs, including panels organized under the auspices of numerous discourse theory conferences over the last decade or so.

Psychoanalysis is attractive to both post-Marxist discourse theorists and early Frankfurt School critical theorists because it offers a vocabulary within which to understand how structures that appear to be 'out there' - structures of economy, biological sex, race, etc. can come to inhabit us, making them feel personal, intimate, and natural. In this view, processes of identification, transference, introjection, and projection, among others, elucidate how the family, the school, the media, and so on, mediate between regimes of production (or consumption, sex, race, etc.) and the construction of our selves. However, one notable difference in the two approaches comes from the emphasis post-Marxists attribute to the 'linguistic turn', at least as inflected through Derridean deconstruction and Lacanian psychoanalysis. Frankfurt School theorists were of course highly sensitive to the rhetorical function of language, including how ideological meanings were transmitted and reinforced through the culture industry, but one effect of making the role of language and theories of discourse an explicit component of the post-Marxist enterprise has been to make it easier to see and explore affinities with other types of discourse analysis, such as conversational analysis, discursive psychology, critical discourse analysis, Foucauldian discourse analyses, rhetorical political analysis, and so on.

Why should discourse analysts, rightly sensitized to the role of language in understanding the process of meaning-making, be interested in what psychoanalysis has to offer? In a first approach one can understand the psychoanalytic contribution in terms of a distinction between two sorts of meaning, in order to then explore how one (deeper meaning) shapes the other (conscious meaning). Although it tends to eschew psychoanalytic terminology, 
cognitive (or conceptual) metaphor theory adopts just such an explanatory frame (Lakoff and Johnson 1980). For example, it might explain voting patterns (conservative versus liberal) with reference to the dominant family metaphor informing voter household dynamics (authoritarian versus permissive, respectively). While there is something to be said about this approach, some scholars caution against a tendency to see these 'deep' metaphors predominantly in neuro-cognitive terms that underplay the unconscious dynamics animating the production, sustenance, or transformation of discourse and thought (Caspi 2018). But approaches that emphasize the emotional aspects of social and political life can - somewhat paradoxically at first sight - also close off from view the unconscious dynamics at play. Hence, in contrast to psychological approaches that identify and catalogue emotional dispositions, treating them as reified mechanisms to explain social and political behaviour, psychoanalytically-informed discursive psychologists highlight the contextual dynamics that constitute emotions (Parker 2010; Billig 1997). From a psychoanalytic point of view, then, feelings can be just as ideological as strongly held beliefs and so it becomes incumbent upon the discourse analyst to also identify the psycho-dynamics by which they are constructed and sustained. So while it is true that Lacanian psychoanalysis and discourse analysis share common cause in the central importance they attribute to language and linguistics, psychoanalysis supplements this appeal to language with an appeal to the dynamics of intersubjective engagement and investment. Critical fantasy studies suggests that a turn to the category of fantasy offers a way to make this double appeal palpable, and in doing so delineates a frontier in post-Marxist discourse theory with considerable research potential.

\section{Fantasy and/in Post-Marxist Discourse Theory}

The articulation of psychoanalysis and discourse analysis through fantasy can be appreciated with reference to the axiomatic assumptions of Laclau and Mouffe's post-Marxist discourse theory. For a start such a poststructuralist framework assumes that structured fields of meaning called discourses constitute a fundamental starting point for any adequate understanding of practices and institutions, including the subjects, objects, and identities making them up. However, an absolutely crucial supplementary assumption informing this approach suggests that such discourses are also marked by contingency. This is often qualified as 'radical' contingency because it is understood to 'go all the way down', an idea that resonates with several categorial names that point to similar theoretical intuitions, such as undecidability (Derrida), dislocation (Laclau), excess (Deleuze and Guattari), and lack in the Other (Lacan).

Radical contingency is understood to 'go all the way down' because it captures something fundamental about how our symbolic system is constitutively incomplete. It is not simply the case that 'things could be otherwise', though this will do as a first approximation. It is also not just that we cannot account for something within the context of an existing symbolic schema due to the complexity or abundance of the world. Rather, 'radical contingency' captures 
something about the incompleteness of the symbolic universe itself. What a (Lacanian) psychoanalytic perspective adds to this picture is the insistence that this constitutive incompleteness also marks the subject. In other words, Lacan draws our attention to the way the openness of the system of meaning is registered in the subject's experience, as anxiety for example. And this, in turn, enables us to directly articulate this constitutive incompleteness, this 'lack in the Other', with fantasy, enjoyment, and desire, bringing us a step closer to addressing questions of affect and passion.

Fantasy is thus a category that enables us to thematize key debates and tensions in discourse theory around the role that affect, passion, and matter can play in their relation to political struggles and questions of method and critique. Chantal Mouffe and Yannis Stavrakakis, among others, have repeatedly emphasized the importance of making passion and affect central to our political analyses and our deliberations about hegemony and political strategy (Mouffe 1993, 115; Stavrakakis 2009). Similarly, Ernesto Laclau insists that "something belonging to the order of affect has a primary role in discursively constructing the social" (Laclau 2004, 326).

However, this does not by any means imply there is a consensus about how to conceptually grasp the relationship between affect and discourse (see, for example, Glynos and Stavrakakis 2004; Laclau 2004; Laclau 2010). In fact, the significance of fantasy for discourse theory lies precisely in the idea that while it remains part of discourse, its habitat stretches to the limits of discourse. Critical fantasy studies can thus be conceived as a frontier of post-Marxist discourse theory that seeks to promote greater attention to conceptual, critical, and methodological issues pertaining to the question of discursive limits, giving a new lease of life to the spirit of the early Frankfurt School and similar enterprises. In fact, a helpful framework within which to situate this ambition of Critical Fantasy Studies resides in the so-called 'logics approach', developed within the auspices of the Essex School in Discourse Theory (Glynos and Howarth 2007), where the logic of fantasy is explicitly added as an analytically separate logic, sitting alongside the social and political logics appearing in the work of Laclau and Mouffe. Yet, aspects of discourse theory at the juncture of psychoanalysis and discourse analysis still remain underdeveloped. As some of the methodological challenges and opportunities associated with taking fantasy seriously have already been sketched out elsewhere (Glynos et al. 2019; Lapping \& Glynos 2019; Glynos 2011, 2010), in what follows I focus primarily on the theoretical and critical dimensions of Critical Fantasy Studies, conceived as a frontier of post-Marxist discourse theory.

\section{Questions of Theory: Fantasy \& Enjoyment}

One key insight animating the turn to critical fantasy studies obviously has something to do with the concept of fantasy itself. "There is no way of understanding political identities and destinies without letting fantasy into the frame" claims the literary theorist, historian, and political thinker Jacqueline Rose $(1996,4)$. An appeal to fantasy is attractive to critical political 
theorists for several reasons, not least because it enables us to reconfigure our understanding of ideology in a way that does not make falsehood a requirement of its application, nor in a way that identifies it as a particular constellation of ideas, however important this latter aspect of ideology is and should remain.

What a psychoanalytic understanding of fantasy tries to capture is the idea of overinvestment or enjoyment. I will expand briefly on this idea shortly, but for now it is worth noting that this idea is attractive from the point of view of critical political theory because it speaks directly to the way we are gripped by certain norms and ideas and identities, but also because it taps into a related network of concepts for thinking about problems of reform and transformation - whether social, economic, or political. It can speak to issues linked to resistance to change and transformation, just as much as issues linked to our ready embrace of change and transformation. Each can be looked at fruitfully through the filter of fantasy and enjoyment because they offer ways of drawing out insights linked to the unconscious, especially as regards dynamic understandings of the unconscious. Issues concerning resistance to change, or its opposite, the embrace of change, thus carve out an abstract problem domain that notions of fantasy and enjoyment can help us navigate in a productive manner. For example, this conceptual framework allows us to tackle questions in and around ideology, something that the work of a (growing) number of scholars have been at pains to draw out (Zizek 1989; Stavrakakis 1999).

A relatively straightforward way to see how these concepts can have a bearing on questions of ideology is to refer to the now commonplace cliché that appeals to the 'facts of the matter' only go so far in the game of persuasion. This is a point brought into sharp relief in a context in which we regularly confront claims about 'alternative facts', or when we casually hurl the term 'fake news' at people whose views we don't share, or when we affirm that we are living in a 'post-truth' era. From a psychoanalytic point of view, that which escapes 'facts of the matter', as well as allied expressions like 'rational self-interest', can be approached in many ways. Fantasy is obviously one of those ways and, as noted earlier, enjoyment is particularly relevant here, at least as this term is understood by the French psychoanalyst Jacques Lacan. According to him enjoyment is not reducible to pleasure, since it is also often associated with a kind of pleasure-in-pain that is closely intertwined with desire and drive. Lacan used the concept of jouissance to capture this idea, and in one of his more colourful formulations he states that on the path of jouissance "once you have started, you never know where it will end. It begins with a tickle and ends in a blaze of petrol" (Lacan 2007, 72). From this point of view, perhaps we could say that fantasy is the frame within which the attractions and threats of enjoyment become legible for the subject.

Everyday understandings of fantasy of course tend to oppose it to reality and the 'facts of the matter'. However, one of the most intriguing insights that psychoanalysis brings to bear on debates about ideology is the idea that fantasy is precisely not opposed to reality or 'facts of 
the matter', at least not necessarily so. What is important from the point of view of fantasy is that it is aligned with desire, not that it opposes some notion of representational truth. Ideology and representational truth certainly intersect, but they do so in the way that vectors intersect on a plane: they intersect, but without necessarily pointing in opposite directions. This psychoanalytic insight with respect to ideology can be brought out neatly by juxtaposing two claims:

1. A statement may be no more ideological for being false

2. A statement may be no less ideological for being true

One way of starting to unpack these statements is to point out how the false character of a claim is not in itself sufficient to elevate it to the level of desire or enjoyment. In other words, just because a statement is false, this does not mean it is also ideological. For example, executive officers may falsely insist that their company's financial accounts have not been 'massaged' to boost its shareholder value (as Jeffrey Skilling and Kenneth Lay did in the heydays of Enron), but a lot more work would be required to show that these false claims and accompanying deceitful practices are also caught up in circuits of desire and enjoyment.

But we can go a step further: not only is the falsity of a claim not sufficient to transform a statement into a statement about enjoyment and thus ideology, it is also not necessary. In fact, a statement may be no less ideological for being true. Or to put it in more straightforward terms: a statement may be thoroughly ideological while at the same time being true, in the sense of representing reality faithfully. This is the take-away insight that underpins Lacan's claim that just because his or her partner is found to be having an affair as a 'matter of fact' this does not mean that a person's jealousy cannot still be treated as pathological (see Zizek $1989,48)$. Or to take another example, while it may very well be true as a 'matter of fact' that the LGBTQ+ community demands 'more and more' rights in 'more and more' domains (e.g., employment rights, church governance rights, marriage rights, property rights, and so on), this does not mean that such a statement - as articulated by right-wing agitators - is innocent, since it is not uncommon for it to be delivered in a way that attributes to the LGBTQ+ community an excessive impulse that can be readily presented and experienced as threatening. What makes something appear invested with enjoyment - and in this sense ideological - is not linked to the issue of whether it conforms to a notion of representational truth (i.e., whether it corresponds to a consensus reality) so much as how it is caught up in a fantasmatic narrative governed by a logic of desire. From a psychoanalytic point of view, then, ideology is linked to a subject's fantasmatic investment in an idea or practice, not its epistemological status as false.

Another way to unpack the theoretical significance of the idea of fantasmatic investment is through an appeal to the further psychoanalytic insight that what binds a community together is often not simply an identification with a common ideal like 'justice' or 'freedom', but also 
an identification with a common form of transgression; and in particular the fantasmatic enjoyment derived from this transgression - an enjoyment often supported with reference to a readily available alibi. Consider for example the great thrill experienced at witnessing politically correct liberals being flummoxed. We can refer here to one of William Connolly's astute observations about the role the SUV played in George W. Bush's 2004 presidential campaign. The SUV served literally and metaphorically as a vehicle that carried a message designed to poke fun at the politically correct establishment and also to capture something about this process of enjoyment in transgression. After Bush's entourage sped around a NASCAR track attended by tens of thousands of fans

Bush emerged from the only SUV in the entourage to an incredible roar of approval. The crowd responded to the SUV as a symbol of disdain for womanly ecologists, safety advocates,... worry-warts about global warming, weak-willed pluralists, and supporters of international accords such as the Kyoto Treaty. Bush played upon the symbol and drew energy from the crowd's acclamation of it. But [and this is the moment of the 'alibi'] his handlers could say - [when] asked - that "he just happened" to ride in that vehicle, sending a surge of joy through followers who both love the message and the way it flummoxes critical commentators. (Connolly 2008: 54-5)

Related to this enjoyment is the sort of enjoyment associated with what we could call bare faced mega lies as a particularly dramatic species of false news, alternative facts and conspiracy theories in a post-truth era. Consider Trump's claims about attendance figures at his inaugural speech, to which one could add examples almost ad infinitum, such as dogmatic climate sceptic claims, or claims that the earth is in fact flat, or claims that the moon landing is a hoax, or claims by Bolsonaro that the Amazon fires were initiated by environmental activists and NGOs. In line with the observations made earlier, what is important about such claims from a psychoanalytic point of view is not so much that these are false, so much as the way they serve to mobilize desire and forge identities. What such claims do, ultimately, is bamboozle a liberal elite wedded to the sanctity of objective facts and figures and rationality. This is not to deny that these claims often distract us from what is 'really going on'; indeed, identifying the strategic or tactical aspects of bare faced mega lies are indispensable to their critical analysis. A psychoanalytic perspective simply insists that what is at stake is also the dynamic construction and sustenance of a collective identity that leans heavily on viscerally potent affective registers (see also Connolly 2017: 29-30). What brings people together is, in part, a collective form of enjoyment whose source resides in liberal elites being flummoxed and at a loss about how on earth to respond, since these claims defy the senses and transgress established common sense in such a spectacular way.

What is particularly noteworthy regarding such bare faced mega lies, not to mention their proliferation and 'stickiness', is that we appear to have less a transgression of any one particular truth than an attack on the conditions of possibility of setting up a truth regime in 
the first place. Or if we insist on calling it a transgression, it appears to be of a rather fundamental sort. It is not so much about transgressing a boundary, as it is about attacking the very idea of a boundary. And this is truly horrifying, because it literally takes the feet away from under us: what appears to be at stake are the very rules that make possible the production of credible statements - whether cashed out in moral terms (as in the case of PC wars) or in epistemological terms (regarding knowledge claims about climate change for example). The target of such attacks, in other words, is not so much what is being said so much as what lends authority to what is being said. When, for example, the subject position of a professional politician or a climate scientist is disqualified in advance, one becomes entirely indifferent to the statements being uttered by such a figure. It could be argued that the subject positions of Hilary Clinton and the liberal mainstream media as a whole were discredited in advance by Trump's supporters in just this way during the 2016 US presidential campaign, accounting for Teflon Trump's capacity to weather otherwise cataclysmic criticisms of all sorts. Still, what is important from a psychoanalytic point of view is how such norm transgressions - some more fundamental than others - can provoke fantasmatic enjoyments that create and sustain forms of collective identification which, under certain conditions, can also foster and sustain rather extreme forms of polarization.

So the term 'fantasy' in Critical Fantasy Studies signals that what is at stake in such studies is a more systematic attempt to foreground and explore what exactly psychoanalytic thought brings to bear on issues connected to claims about reality, morality, rationality, and other 'facts of the matter'. Here, fantasy - and associated psychoanalytic concepts and insights simply serves as a potentially productive entry point for such studies (see, for example, Ormrod 2014). And this in turn opens up an interesting research pathway, calling for a theoretical and speculative comparative inquiry into how fantasy and other psychoanalytic categories can produce revealing insights when juxtaposed to, and contrasted with, other key categories drawing on other traditions: reification, fetishism, structures of feeling, rhetoric, myth, narrative, metaphor, utopia, and so on. Rhetoric, to take just one example, appears to be a promising concept for such a comparative exploration, particularly as elaborated by scholars such as Alan Finlayson (2012) and James Martin (2014; 2016). At least two features of their work are worth commenting on. First, their brand of 'rhetorical political analysis' already constitutes a reactivation and deconstruction of classical rhetorical categories, rearticulating them in a way that is compatible with basic poststructuralist presuppositions and thus directly pertinent for post-Marxist discourse theory scholars. In addition, however, recent work has suggested conceptualizing rhetorical persuasion also as a way of 'capturing desire' (Martin 2016). This opens up a terrain rich for further comparative-conceptual investigation within the field of critical fantasy studies.

\section{Questions of Critique: Normative and Ideological Critique}

So far I have focused on the theoretical and conceptual aspects of critical fantasy studies. What about the critical aspects? The explicit invocation of the term 'critical' already indicates 
that engaging in fantasy studies should matter from a critical point of view. So it is important to be precise about what this entails. The idea of critique here is understood both normatively, in terms of the kind of concrete programs that might be promoted by certain sets of practices, and ideologically, at least in its psychoanalytic sense, as understood by scholars such as Laclau, Mouffe, and Zizek. The qualifier 'normative' is here meant to refer broadly to the norms, ideals, principles or policies associated with one or another social, economic, or political programme; and it tends to presuppose one or another theory of society, broadly conceived. The qualifier 'ideological', however, is not reducible to ideas or ideational content, in the way we refer to conservatism, liberalism, socialism, or nationalism as ideologies. As I noted earlier, the invocation of the term ideology is aiming to capture something not simply about ideas or norms but about the fantasmatically-inflected way we engage with them, the way we are invested in them emotionally, the way we identify with them.

From an ideological point of view - rather than simply from a normative point of view - a movement, party, or discourse can therefore be linked to different forms of affective investment, depending on how the subject mediates the content of that discourse with one or another fantasy: fantasies of racial or ethnic purity, nostalgic fantasies of past glory, fantasies of mastery or self-sufficiency, fantasies of a Caring Other, and so on. Do we engage with this content in open ways that affirm their uncertain character and that acknowledge our anxieties and doubts, or in ways that can be characterised as 'closed', rooted in ressentiment, hatred, fear, and threats projected onto others?

The widely reported MPs' expenses scandal in 2009 can serve to illustrate this difference between the normative content associated with fantasy and the ideological mode of fantasmatic investment in this content (Chang and Glynos 2011). The scandal centred on the uproar provoked by the abuse visited upon the expenses system by British MPs over many years. At the level of content, it is possible to show how collective fantasies of 'individual selfsufficiency' and 'paternalism' point to distinct normative visions of a future polity in response to the scandal: the elimination or reduction of state expenditure and public services; or, on the contrary, the reform of, and increased support for, the state apparatus and public services. However, beyond this difference in normative content, it was also possible to discern a common mode of fantasmatic ressentiment, undergirded by a shared over-investment in nostalgic ideas of past honour and glory, understood to be pure and under imminent threat of corruption, whether from the inside or the outside.

In fact, this type of analysis raises a more general question about ideological critique itself, as opposed to normative critique. If we accept that effective forms of ideological critique cannot always or so easily rely on appeals to common empirical or moral sense; if we accept that the descriptive and normative aspects of critique cannot and should not be understood to exhaust its purview; if we accept the need for a conception of ideology that takes seriously 
the fantasmatic dimension of social and political life, we can then ask: What are the conditions under which we can imagine a form of critique that would transform our relation to (fantasmatically-mediated) modes of over-investment, particularly those broadly understood to belong to the family of ressentiment?

In addressing this question it is worth turning to another psychoanalytic category - the category of mourning - in part because it can be readily be brought into a productive relation with fantasy (see also Butler 2006; Glynos 2014). To understand why an appeal to mourning might be promising in this context it is worth emphasizing how the force of our attachment to others, and what often makes mourning their loss so difficult, is linked not so much to the specific content of a mediating fantasy as it is to the fact that this content and its significance tend to resist disclosure. Fantasy's natural habitat is 'between the lines', so to speak, and so the way someone matters to us can thus often appear rather opaque. The paradox of fantasy is that it tends to dwell somewhere beyond our conscious deliberations and thoughts, always just out of reach, and yet it also appears to be absolutely central in defining who we are. A key critical insight of psychoanalysis, however, suggests that the 'grip' of a fantasmatic narrative tends to lose its force when it becomes articulated as a (fantasmatic) narrative. It is for this reason that the integration of the concept of mourning into a critical fantasy studies enterprise appears promising.

In a first approach we could say that an appeal to mourning is helpful in thinking about the process of detachment as a process of fantasy construction. Mourning implies the loss of something that is significant to us, often linked to a person we love. In other words, it addresses a problem about the loss of our identity support. But, as noted, the meaning and significance of this loss can often elude us, even as this loss is and remains deeply felt. Mourning, therefore, entails a process of construction since, by means of slowly building up a narrative, we can begin to make some sense of this loss, and in doing so start the process of (creative and constructive) detachment from our identity (over-)investments, our modes of enjoyment and their fantasmatic support. From the perspective of political theory, mourning can thus be readily understood as a component part of a critique of ideology (see also Glynos \& Voutyras 2016). In the case of the MPs' expenses scandal referred to above, this might demand some level of creative experimentation with collective spaces of deliberation in which it would be possible to entertain troubling ideas without immediately suppressing them or projecting them onto others - for example, the idea that our historical and democratic legacy was never as pure as we imagined it, or that it is rather inconsistent and incomplete, inviting collective efforts at re-imagining and constructing alternative futures. It might turn out that experimental spaces of radical democratic deliberation construed broadly enough to incorporate the dimension of mourning and thus processes of collective fantasmatic construction - would be particularly appropriate in situations of extreme political polarization, but I suspect that it would be relevant also in less polarized 
contexts, whether at a macro-political level or at a more quotidian level, connected to the household or the workplace, for example.

However, an appeal to mourning, understood now also as ideological critique, also provokes a set of more targeted questions, which I can only briefly touch on here, about the conditions under which it can take place. Setting aside admittedly important educational and pedagogical pre-conditions, we can - in Gramscian fashion - explore these questions in relation to state-specific sites as well as civil society sites, involving, for example, the construction of monuments, sculptures, or other forms of public art and cultural artefacts. Moreover, these questions about mourning's conditions of possibility, which carry both normative and ideological significance, are as pertinent for dealing with the collective fantasies undergirding our social and political identities, ideals, and discourses as they are for dealing with individual fantasies.

In sum, the qualification 'critical' in Critical Fantasy Studies is meant to capture something about how such studies seek to draw out the normative, ideological, and politico-strategic implications of specific psychoanalytic insights and observations, and thus become part of a broader enterprise in critical empirical and theoretical research. However, this is just the beginning of the sorts of issues a critical fantasy approach might try to thematize, because, it is precisely at this point that things start to get messy.

\section{Concluding Caveat: Not all that is not conscious is unconscious}

My final, concluding set of comments can be seen as a kind of cautionary remark, or rather an attempt to inject some modesty into any sort of critical fantasy studies endeavour. This is because a psychoanalytic characterization of phenomena may lead us to exaggerate the role of affect and unconscious enjoyment in accounting for both the fascination and inertia of such phenomena. It may suggest that a critical explanation of, for example, the Trump, anti-Trump, Brexit or anti-Brexit phenomena, can be entirely - or predominantly - understood in terms of the culturally-inflected fantasies that make such enjoyments possible. We need to guard against this kind of psychoanalytic imperialism, akin to a kind of economic imperialism, whereby a particular economic category like class becomes a substantive first cause, rather than a highly productive entry point. Perhaps we can summarize these cautionary observations in the expression "NOT ALL THAT IS NOT CONSCIOUS IS UNCONSCIOUS".

This phrase expresses the idea that not all that is not subject to conscious cognitive apprehension and rational control can or should necessarily be understood with reference to the Freudian unconscious. In many ways this may seem like stating the obvious. Affirming this idea, however, does not simply serve to inoculate us against temptations of aggrandizement. It also implies affirming the challenge to tackle the rather tricky question of how to incorporate other factors into our account, including non-conscious factors that are nonunconscious; what relative 'weights' to attribute to them; how to conceptualise their inter- 
relationships; how to articulate them; and so on. If not all that is not subject to conscious individual or collective control is reducible to unconscious processes, a critical fantasy studies approach must be ready to engage with and combine prima facie heterogeneous factors often the focus of distinct disciplines - such as coercion (physical, financial, mental), institutional norms, social and political logics, competing normative values, causal mechanisms, fantasmatic enjoyment, and so on.

There are thus a wide range of phenomena and issues on which critical fantasy studies could be brought to bear, which can be organized illustratively, though somewhat arbitrarily and not unproblematically, into a number of domains: the domain of the economy (concerning processes of production, competition, exchange, consumption, as well as the expropriation and distribution of surplus labour); the domain of politics and governance (concerning different forms of organization centred around questions of justice, democracy, and hegemony, whether party-political in character or oriented toward community organizing and grass-roots mobilisation); the domain of nature (concerning the inanimate physical world and the living world, incorporating issues linked to climate change and the sexed body, for example); the domain of society (concerning the domestic and work spheres, the cultural and media spheres, the spheres of arts and education, as well as prefigurative forms of experimental living); the domain of methodology (concerning research processes not just in an academic context, but also in policy and wider civil society contexts). One can imagine such a transdisciplinary research endeavour taking place in dialogue with other approaches, spanning the full gamut from those that share clear affinities with the critical explanatory impulse of post-Marxist discourse theory all the way to those approaches that abide by the more conventional explanatory imperatives of social science. Given the early Frankfurt School's rich heritage of engaging with many of these issue domains, and given its effort to think through and carefully navigate the relationship between psychoanalysis, social science, culture, and the critique of political economy, I suspect that a lot can be gained by making a more systematic effort to bring work informed by this perspective more fully into the orbit of post-Marxist discourse theory. Critical fantasy studies can serve as one way to further explore and deepen this relationship, while reaching out to other approaches as well, inspiring new takes on the relationship between the unconscious and non-unconscious dimensions of social and political life.

\section{Acknowledgements}

For helpful and constructive feedback I thank Benjamin De Cleen, Yannis Stavrakakis, and JLP's anonymous reviewers. This article has been inspired by conversations I have had over several years with colleagues too many to list exhaustively, including Randi Gressgård, Robin Klimecki, Claudia Lapping, Lynne Layton, Yahya Madra, Ayşem Mert, Ceren Ozselçuk, Simon Parker, Edouard Pignot, Angelika Sjostedt-Landen, Ewen Speed, Yannis Stavrakakis, Nana Vaaben, Savvas Voutyras, Rebecca Warren, Hugh Willmott, and Karen West; and it has benefited enormously from ongoing critical discussions with colleagues in the Ideology and Discourse 
Analysis programme at Essex, including especially David Howarth and our MA and PhD student cohorts.

\section{References}

Best, Beverley, Werner Bonefeld, and Chris O'Kane, eds. 2018. The Sage Handbook of Frankfurt School Critical Theory. London: Sage.

Billig, Michael. 1997. "'Discursive, rhetorical and ideological messages." In The Message of Social Psychology, edited by Craig McGarty and Alexander Haslam, 36-53. Oxford: Blackwell.

Butler, Judith. 2006. Precarious Life: the Powers of Mourning and Violence. London: Verso

Caspi, Tair. 2018. "Towards psychoanalytic contribution to linguistic metaphor theory." The International Journal of Psychoanalysis, 99 (5): 1186-1211.

Chang, Wei-Yuan, and Jason Glynos. 2011 "Ideology and Politics in the Popular Press: The Case of the 2009 UK MP's Expenses Scandal." in Discourse Theory and Critical Media Politics, edited by Lincoln Dahlberg and Sean Phelan, 106-127. London: PalgraveMacmillan

Connolly, William. 2008. Capitalism and Christianity, American Style. Durham: Duke.

Connolly, William. 2017. Aspirational Fascism. Minneapolis: University of Minnesota Press.

Finlayson, Alan. 2012. "Rhetoric and the Political Theory of Ideologies." Political Studies 60 (4): 751-67.

Glynos, Jason. 2010. "Lacan at Work." In Lacan and Organization, edited by Carl Cederstrom and Casper Hoedemaeker, 13-58. MayFly Books.

Glynos, Jason. 2011. "On the Ideological and Political Significance of Fantasy in the Organization of Work." Psychoanalysis, Culture \& Society 16 (4): 373-393.

Glynos, Jason. 2014. "Death, Fantasy, And The Ethics Of Mourning." In The Social Construction of Death Interdisciplinary Perspectives, Edited by Leen Van Brussel and Nico Carpentier, 137-160. London: Palgrave Macmillan.

Glynos, Jason, Joanildo Burity, and Gustavo Oliveira. 2019. "Critical Fantasy Studies: Neoliberalism, Education, Identification." Serie-Estudos 24 (52): 145-170.

Glynos, Jason and David Howarth. 2007. Logics of Critical Explanation in Social and Political Theory. Abingdon: Routledge.

Glynos, Jason and Savvas Voutyras. 2016. "Ideology as Blocked Mourning: Greek National Identity in Times of Economic Crisis and Austerity." Journal of Political Ideologies 21 (3): 201-224. 
Glynos, Jason and Yannis Stavrakakis. 2004. "Encounters of the Real Kind: Sussing Out the Limits of Laclau's Embrace of Lacan." In Laclau: A Critical Reader, edited by Simon Critchley and Oliver Marchart, 110-128. London: Routledge.

Lacan, Jacques. 2007. Seminar XVII: The Other Side of Psychoanalysis. NY: Norton.

Laclau, Ernesto. 1990. New Reflections on the Revolution of Our Time. London: Verso.

Laclau, Ernesto. 2004. "Glimpsing the Future: A Reply." In Laclau: A Critical Reader, edited by Simon Critchley and Oliver Marchart, 279-328. London: Routledge.

Laclau, Ernesto. 2010. "Politics and the Unconscious: An Interview." Subjectivity 3: 231-244. Laclau, Ernesto and Chantal Mouffe. 1985. Hegemony and Socialist Strategy. London: Verso. Lakoff, George and Mark Johnson. 1980. Metaphors We Live By. Chicago: University of Chicago Press.

Lapping, Claudia and Jason Glynos. 2019. "'Two for joy' - Towards a better understanding of free associative methods as sites of transference in empirical research." Psychoanalysis, Culture \& Society 24 (4): 432-451

Layton, Lynne. 2020. Toward a Social Psychoanalysis. London: Routledge.

Martin, James. 2014. Politics and Rhetoric: A Critical Introduction. Abingdon: Routledge.

Martin, James. 2016. "Capturing Desire: Rhetorical Strategies and the Affectivity of Discourse." British Journal of Politics and International Relations 18 (1): 143-160.

Morelock, Jeremiah, ed. 2018. Critical Theory and Authoritarian Populism. London: University of Westminster Press.

Mouffe, Chantal. 1993. The Return of the Political. London: Verso.

Ormrod, James. 2014. Fantasy and Social Movements. London: Palgrave Macmillan.

Parker, Ian. 2010. "Psychosocial studies: Lacanian discourse analysis negotiating interview text." Psychoanalysis, Culture and Society 15 (2): 156-172.

Rose, Jacqueline. 1996. States of Fantasy. Oxford: Clarendon Press.

Stavrakakis, Yannis. 1999. Lacan \& the Political. London: Routledge.

Stavrakakis, Yannis. 2009. "Discourse and Affect: Conceptual and Political Dialectics in Theory and Empirical Analysis." 59th Annual Meeting. Political Studies Association. Manchester, UK.

Zizek, Slavoj. 1989. The Sublime Object of Ideology. London: Verso. 